\title{
O abajurú (Chrysobalanus icaco L. e Eugenia rotundifolia Casar.) comercializado na cidade do Rio de Janeiro, Brasil
}

\author{
Inês Machline Silva*,1 Ariane Luna Peixoto \\ ${ }^{1}$ Departamento de Botânica, Instituto de Biologia, Universidade Federal Rural do Rio de Janeiro, Rodovia BR \\ $465 \mathrm{~km}$ 7, 23890-000 Seropédica-RJ, Brasil, \\ ${ }^{2}$ Instituto de Pesquisas, Jardim Botânico do Rio de Janeiro, R. Pacheco Leão 915, Jardim Botânico, 22460-030 \\ Rio de Janeiro-RJ, Brasil
}

\begin{abstract}
RESUMO: Este artigo analisa as prováveis razões de introdução e comercialização de uma espécie de uso medicinal em um mercado popular urbano na cidade do Rio de Janeiro, Brasil - o Mercado de Madureira. Durante os anos de 2005 e 2006 aplicaram-se entrevistas semi-estruturadas a 15 erveiros obtendo-se o freelist das espécies consideradas como mais comercializadas (97) a partir do qual se calculou o índice de saliência, que para o abajurú (Eugenia rotundifolia Casar), foi elevado. A espécie conhecida na literatura e comercializada como abajurú é Chysobalanus icaco L., que apresenta propriedades hipoglicemiantes comprovadas por pesquisas farmacológicas e é utilizada pela população para este fim; no entanto, verificouse, nesse mercado, a venda quase exclusiva de E. rotundifolia, com esse nome popular e mesma propriedade. Até o momento não existem dados farmacológicos para essa espécie. Ambas são nativas e ocorrem, predominantemente, nas restingas litorâneas do estado do Rio de Janeiro. A atribuição da atividade hipoglicemiante a E. rotundifolia pode indicar uma correlação, por parte dos erveiros, com a farmacologia de outras espécies de Myrtaceae. Questões relacionadas à fiscalização ambiental bem como desconhecimento e coleta equivocada podem também estar envolvidos nesse processo.
\end{abstract}

Unitermos: Chrysobalanus icaco, Chrysobalanaceae, Eugenia rotundifolia, Myrtaceae, etnobotânica, plantas medicinais, restinga, extrativismo, mercado popular.

\begin{abstract}
Abajurú (Chrysobalanus icaco L. and Eugenia rotundifolia Casar.) commercialized in Rio de Janeiro, Brazil”. The present paper analyzes the commercialization of a new medicinal specie in a public market in Rio de Janeiro, Brazil. During the years 2005-2006 semi-structured interviews were made with 15 herbalists. A free list of the most commercialized species (97) was made, and calculated the salience index in witch Eugenia rotundifolia presented a high value. Chrysobalanus icaco is known in the literature as sold as abajurú, and has hipoglicemient properties, proven by pharmacological research. The local population uses this species for these properties, however in the market in question, E. rotundifolia is almost exclusively sold with the same popular name and medicinal property. Until the present time, no pharmacological data exists for this specie. Both species are native and predominantly present in the coastal formations (restinga) of Rio de Janeiro. The attribution of the hipoglicemient property of $E$. rotundifolia may indicate a correlation, made by the herbalists, with the pharmacology of other Myrtaceae species. The lack of knowledge, erroneous field surveys and problems related with environmental monitoring may be involved with this process.
\end{abstract}

Keywords: Chrysobalanus icaco, Chrysobalanaceae, Eugenia rotundifolia, Myrtaceae, ethnobotany, medicinal plants, restinga, harvest, public market.

\section{INTRODUÇÃO}

Pelo potencial de uso que apresenta, Chrysobalanus icaco L. tem sido recorrentemente citado na literatura. Pescadores da América e África cozinham sua casca e utilizam para tingir, endurecer e tornar mais duradouras as suas redes (Pio Corrêa, 1926; Fonseca-Kruel et al., 2006). Seus frutos com uma polpa branca e adocicada são comestíveis e em muitos

*E-mail: machline@ufrrj.br,Tel.+55-21-3244-1576 países utilizados como doces e em conservas, sendo em alguns locais comercializados em feiras e mercados (Pio Corrêa, 1926; Braga, 1960; Ferrão 1999; Ugent \& Ochoa, 2006). O óleo da semente era outrora aproveitado para preparação de uma emulsão antidiarréica e para ungüentos (Pio Corrêa, 1926). Suas raízes, cascas e folhas são adstringentes e utilizadas contra disenterias, catarro de bexiga, leucorréias (Pio Corrêa, 1926; Freise 1934; Roig y Mesa, 1945; Wong, 1976; Hoehne, 1978; 
Agra et al., 2008) e pedra nos rins (Fonseca-Kruel et al., 2006). O potencial como agente anti-tumoral (Fernandes et al., 2003) e também no combate ao diabetes mellitus foram amplamente divulgados na literatura (Costa, 1977; Pereira, 1997; Lorenzi \& Matos, 2002; FonsecaKruel et al., 2006; Albuquerque et al., 2007). É utilizada também como planta ornamental na América do norte.

O diabetes atinge aproximadamente 35 milhões de pessoas nas Américas (Sartorelli \& Franco, 2003) e, particularmente no Brasil, cerca de 11 milhões de pessoas, segundo a estimativa da Sociedade Brasileira de Diabetes (Netto, 2007). Desta forma compreendese porque inúmeras espécies vegetais são utilizadas no mundo para minimizar suas conseqüências (Bnouham et al., 2006; Funke \& Melzig, 2006; Cavalli et al., 2007; Torrico et al., 2007; Figueiredo \& Modesto-Filho, 2008; Janebro et al., 2008). No Brasil cerca de 200 espécies são usadas para este fim, sendo que 52 foram estudadas experimentalmente e apresentaram atividade analgésica, antiinflamatória e hipoglicemiante comprovada (Barbosa-Filho et al., 2005). Dentre estas, C. icaco vem apresentando excelentes resultados (Presta \& Pereira, 1987; Castilho et al., 2000; Mors et al., 2000; BarbosaFilho et al., 2005; Barbosa et al., 2006). Esta espécie conhecida no Brasil como abajurú, abajerú, bajerú, guajurú, entre outros nomes populares, ocorre no litoral brasileiro e também no litoral dos paises do norte da América do Sul, América Central e México, bem como na costa ocidental da África (Prance, 1972).

Em conseqüência de seu reputado efeito no controle ao diabetes, o comércio das folhas frescas e/ ou secas de $C$. icaco pode ser facilmente verificado tanto em feiras e mercados como na forma de ensacados vendidos, em diferentes estabelecimentos comerciais, na cidade do Rio de Janeiro. Neste sentido, o Mercado de Madureira, localizado na zona norte da cidade, destacase pelo número de erveiros e quantidade de espécies comercializadas. Dentre estas, o abajurú mereceu destaque por ter sido verificada a comercialização simultânea, sob esta denominação popular, tanto de C. icaco, como também de Eugenia rotundifolia (Myrtaceae).

O uso de diferentes táxons, sob uma mesma designação popular não é nova na literatura: a questão da espinheira-santa, no Rio de Janeiro, é um exemplo recente da introdução e absorção, no repertório popular, de espécies morfologicamente semelhantes, mas que não necessariamente apresentam o mesmo efeito farmacológico desejado (Gonzales et al., 2001; Coelho et al., 2002; Coulaud-Cunha et al., 2004). O uso tradicional de espécies de espinheira-santa, na região sul do Brasil para o tratamento de úlceras, foi incorporado na região sudeste. Contudo, naquela região utilizam-se espécies de Maytenus (Celastraceae), enquanto que nas feiras livres do Rio de Janeiro e no próprio Mercado de Madureira verifica-se a utilização de Sorocea cf. bonplandii (Moraceae) como tal.

O presente trabalho objetivou registrar a venda de $C$. icaco e $E$. rotundifolia, sob a mesma designação popular, bem como discutir as prováveis causas e implicações envolvidas nesse processo.

\section{MATERIAL E MÉTODOS}

Ao longo dos anos de 2005 e 2006 foram aplicadas 51 entrevistas semi-estruturadas (Bernard, 1995) para levantamento de dados etnobotânicos a 15 erveiros (num total de 28) que comercializam ervas medicinais e/ou rituais no Mercado de Madureira. Utilizou-se a técnica conhecida como "bola de neve" indicada para uma população altamente especializada e de pequeno número de integrantes (Appolinário, 2006). Para tal, um informante-chave, previamente conhecido, indicou outra pessoa a ser entrevistada e assim sucessivamente. Esse mercado foi criado em 1914, tornando-se, a partir de 1929, o maior centro de distribuição de alimentos da zona suburbana do Rio de Janeiro. Apresenta hoje aproximadamente 700 boxes para venda de muitos produtos variando de alimentação, utensílios domésticos, papelarias, drogarias e principalmente de comércio de artigos religiosos, incluindo-se aí, a venda de animais para sacrifícios. No local reservado aos hortifrutigranjeiros encontram-se 28 boxes de plantas comercializadas para fins medicinais e ritualísticos, que muitas vezes vendem também temperos, legumes e verduras. Esse mercado é um dos grandes fornecedores para feirantes e vendedores ambulantes da cidade (Azevedo \& Silva, 2006).

Os erveiros foram entrevistados durante o período de trabalho e conseqüentemente sem disponibilidade de tempo para longas entrevistas. Assim, optou-se por aplicar a técnica conhecida como listagem livre (freelist) (Martin, 1995; Sutrop, 2001) mais especificamente a lista restrita de tarefas (restricted list task) - na qual cada informante foi estimulado a citar, pelo menos, dez espécies consideradas como mais comercializadas. Cada informante foi entrevistado pelo menos uma vez sendo que mais entrevistas se sucederam para aqueles que continuaram colaborando com a pesquisa que teve objetivos mais amplos do que a questão do abajurú. Para cada espécie foram anotadas informações relacionadas à(s) propriedade(s) etnofarmacológica(s) atribuída(s), formas de uso, parte(s) da planta utilizada(s) e outras informações.

Considera-se que as espécies mencionadas com freqüência indicam consenso ou conhecimento comum entre os indivíduos, dentro de uma determinada cultura. Neste sentido, para verificar o grau de importância das espécies listadas, especialmente do abajurú, no mercado de Madureira, calculou-se o "Índice de Saliência" (Smith, 1993; Martin, 1995; Cotton, 1996) que leva em consideração dois parâmetros: a freqüência e ordem de citação seguindo-se a metodologia recomendada por Quinlan (2005), utilizando-se para tal o software Visual Anthropac-Freelists 4.0 (Borgatti, 1996). Adquiriu-se material botânico das espécies listadas pelos erveiros através de compra e para a identificação do mesmo utilizaram-se chaves analíticas, bibliografia especializada, comparação com exsicatas de herbários e, 
quando necessário, valeu-se do auxílio de especialistas. Foram confeccionadas exsicatas, que se encontram depositadas no herbário do Instituto de Pesquisas Jardim Botânico do Rio de Janeiro (RB). As fotos da Figura 1 correspondem às exsicatas de $C$. icaco (C. Farney \& L.S. Sarayba 2148; RB 279529) e de E. rotundifolia (D.Araújo 7903; RB 389252) depositadas no referido herbário.

O termo etnoespécie é aqui aplicado a duas espécies bem definidas (diferenciadas) do ponto de vista da taxonomia vegetal para as quais os erveiros entrevistados atribuem o mesmo nome popular.

\section{RESULTADOS E DISCUSSÃO}

No levantamento etnobotânico realizado com os erveiros no Mercado de Madureira foram reconhecidas um total de 258 espécies. A listagem livre obteve um rol de 97 espécies que são consideradas como muito comercializadas. Esta técnica de listagem livre é considerada um método etnográfico bem estabelecido, relacionado a fronteiras de domínios culturais, que parte do pressuposto que quando as pessoas listam livremente elas tendem a listar os termos em ordem de familiaridade - os indivíduos que sabem mais sobre o conteúdo solicitado listam mais do que aquelas que sabem menos - e os termos que são mais lembrados indicam que são localmente mais proeminentes (Quinlan, 2005). Na tabela 1 são apresentadas as espécies que mais se destacaram pelo índice de saliência.

O fato do abajurú (E. rotundifolia) aparecer, na tabela, em terceiro lugar, em um rol de 97 espécies, confirma a importância da mesma na farmacopéia popular do Rio de Janeiro. Dentre os 15 erveiros entrevistados, nove citaram e vendiam essa espécie de abajurú para o combate ao diabetes (houve apenas uma citação para "abaixar o colesterol”). Apenas um informante vendia a outra espécie de abajurú (Chrysobalanus icaco) e, por ter sido citada apenas por ele, esta obteve um índice de saliência de apenas 0,07. Entretanto, este erveiro comercializava também E. rotundifolia, designando-a por "abajurú genérico".

As pesquisas comprovaram, até o momento, a eficácia científica de $C$. icaco como hipoglicemiante (Di Stasi \& Hiruma-Lima, 2003), atrelando-a sempre ao nome popular de abajurú (ou nomes correlacionados). Entretanto, não foram encontradas referências etnobotânicas, químicas e/ou farmacológicas indicando o uso de E. rotundifolia, especificamente como tal, apesar de inúmeras pesquisas confirmarem a presença de substâncias com potencial medicinal para esse gênero e para a família Myrtaceae em geral (Almeida et al., 1995; Olajide et al., 1999; Holetz et al., 2002; Coelho de Souza et al., 2004; Ravi, 2004; Barbosa-Filho et al., 2005; Oliveira et al., 2005; Bnouhmam et al., 2006; Oliveira et al., 2006; Donato \& Morretes, 2007; Bertucci et al., 2008; Quintans-Júnior et al., 2008). Também não foram encontrados registros, na literatura, da comercialização desta última com o nome popular de abajurú ou qualquer outro nome.

$\mathrm{O}$ número de espécies vegetais utilizadas no Brasil no combate ao diabetes mellitus era muito menor no passado, mas atualmente, o país desponta na América do Sul como responsável por 23\% das espécies testadas (Barbosa-Filho et al., 2005). Este fato reflete possivelmente uma tendência local (e também mundial) de acentuado incremento na freqüência dessa doença nos últimos anos, ocasionado provavelmente pelo envelhecimento da população e alterações no estilo de vida (Sartorelli et al., 2006). Para C. icaco, por exemplo, a primeira referência encontrada na literatura ao uso como hipoglicemiante foi em 1977 (Costa, 1977) embora outras atividades etnofarmacológicas já eram atribuídas anteriormente para essa espécie (Presta et al., 2007). É provável que a ação hipoglicemiante de C. icaco tenha sido amplamente noticiada a partir do incremento de trabalhos mais recentes, que reiteraram tal atividade, estimulando, desta forma, o seu uso. Neste caso, o crescimento da doença aliado ao empobrecimento da população bem como à falta de acesso aos serviços

Tabela 1. Índice de saliência das 10 espécies mais comercializadas nos anos de 2005/2006 no Mercado de Madureira, Rio de Janeiro, Brasil.

\begin{tabular}{|c|c|c|c|c|}
\hline Espécie & Família & Nome popular & $\begin{array}{l}\text { Documentação } \\
\text { botânica }\end{array}$ & Saliência \\
\hline Mentha piperita L. var. citrata (Ehrh.) Briq. & Lamiaceae & elevante & I.M.Silva 506 & 0,38 \\
\hline Ocimum basilicum $\mathrm{L}$. & Lamiaceae & manjericão & I.M.Silva 529 & 0,36 \\
\hline Eugenia rotundifolia $\mathrm{L}$. & Myrtaceae & abajurú, bajirú, & I.M. Silva 611,740 & 0,35 \\
\hline $\begin{array}{l}\text { Sorocea } \text { cf. bonplandii (Baillon) Burger, } \\
\text { Lanjou \&W. Boer }\end{array}$ & Moraceae & espinheira-santa & I.M. Silva 524 & 0,34 \\
\hline Kalanchoe brasiliensis Cambess & Crassulaceae & saião & I.M. Silva 715 & 0,32 \\
\hline Menyha pulegium L. & Lamiaceae & poejo & I.M. Silva 553 & 0,30 \\
\hline Aeollanthus suaveolens Mart. ex Spreng. & Lamiaceae & macassá & I.M. Silva 590 & 0,29 \\
\hline Vernonia paludosa Gardner & Asteraceae & Assa-peixe & I.M. Silva 806 & 0,22 \\
\hline Baccharis cf. trimera (Less)DC. & Asteraceae & carqueja & I.M. Silva 718 & 0,21 \\
\hline Piper arboreum Aubler var. arboreum & Piperaceae & vence-demanda & I.M. Silva 533 & 0,19 \\
\hline
\end{tabular}


oficiais de saúde nutriram, certamente, o comércio de plantas medicinais ávido por apresentar novas espécies ou atribuir novas atividades farmacológicas a espécies já conhecidas e consumidas anteriormente para outros fins.

\section{Por que Chrysobalanus icaco está sendo substituída por Eugenia rotundifolia?}

Para Albuquerque \& Hanazaki (2006) as dificuldades relacionadas ao entendimento de questões envolvendo os padrões que levam à escolha de espécies, para uso medicinal, devem estar associados a testes de hipóteses. Esses autores salientam que é preciso tentar explicar como as pessoas selecionam plantas e animais para uso medicinal e que critérios envolvem tal escolha. Da mesma forma a substituição de espécies, na medicina popular, deve ser analisada. Assim, as considerações abaixo apontam algumas possibilidades para o caso específico do abajurú.

Chrysobalanus icaco ocorre em diversos estados brasileiros (AM, MA, CE, PA, PI, PE, SE, BA, ES, RJ e SP) (Prance, 1972) e para o Rio de Janeiro foram registradas coletas nos Municípios de Arraial do Cabo, Cabo Frio, Rio de Janeiro e Saquarema (Instituto de Pesquisas Jardim Botânico do Rio de Janeiro, 2007). Ocorre também no Município de Angra dos Reis, na Reserva da Praia do Sul (Ilha Grande) e ao norte do Município de Rio das Ostras (Doroty Sue Dun Araújo, comunicação pessoal).

Apresenta ampla plasticidade para estabelecer-

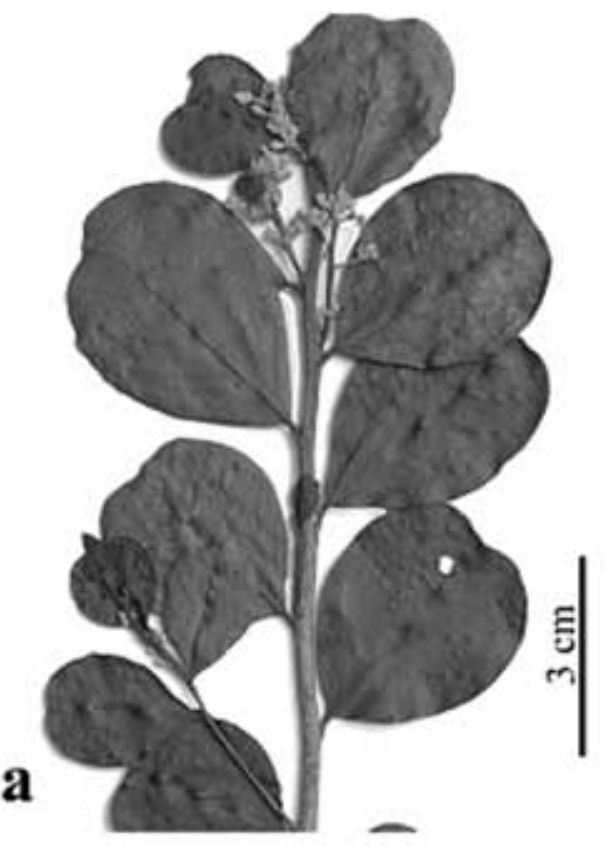

se em diferentes associações vegetais, na vegetação costeira, desenvolvendo-se em brejos, mangues e restingas, em locais sujeitos a déficit hídrico ou a inundação em determinadas épocas do ano e em solos com afloramento de rochas (Santana \& Silva, 2000; Oliveira \& Souza, 2005). Na restinga da Marambaia, entretanto, esta espécie está presente somente na formação vegetacional denominada "arbustiva aberta não inundável”, composta predominantemente por Myrtaceae (Menezes \& Araújo, 2005). Trata-se de um arbusto ou pequena árvore de até 5 metros de altura, freqüentemente com ramos decumbentes, com folhas geralmente orbiculares a ovado-elípticas de $2-8 \mathrm{~cm}$ de comprimento e 1,2-6,0 cm de largura, retusas, arredondadas ou com pequeno acúmem no ápice, base sub-cuneada, glabras em ambas as faces e com pecíolo medindo 2 a $4 \mathrm{~mm}$ de comprimento (Prance, 1972).

As Chrysobalanaceae são morfologicamente distintas das espécies brasileiras de Myrtaceae no que diz respeito a muitos aspectos, dentre eles, a filotaxia, que é alterna (e oposta nas Myrtaceae) e folhas sem pontos translúcidos e nervura marginal, comuns em Myrtaceae. Apesar disso, a forma semelhante das folhas de $C$. icaco e E. rotundifolia pode confundir um leigo (Figura 1).

E. rotundifolia é também um arbusto, de cerca de $2 \mathrm{~m}$ de altura, com folhas opostas, elípticas obovadas ou suborbiculares, ápice arredondado, obtuso ou obtusoacuminado e base arredondada, obtusa ou aguda, bordo revoluto, coriáceas, discolores, densamente pontudas (Souza, 2005). Ocorre nas restingas, principalmente nos

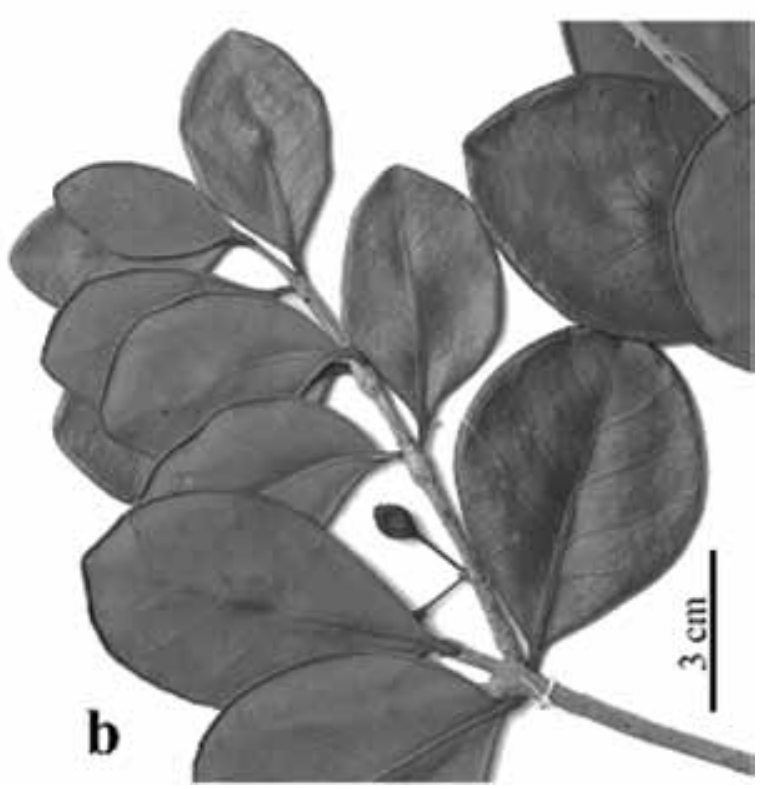

Figura 1. Detalhes dos ramos de Chrysobalanus icaco L. (Chrysobalanaceae) (a) e Eugenia rotundifolia Casar (Myrtaceae) (b) 
estados da Bahia, Espírito Santo e Rio de Janeiro.

Especificamente para o Rio de Janeiro, foram registradas coletas em Armação dos Búzios, Cabo Frio, Carapebus, Macaé, Maricá, Rio de Janeiro, São João da Barra e também em Saquarema (Instituto de Pesquisas Jardim Botânico do Rio de Janeiro, 2007; Souza, 2005).

O trabalho realizado por Pereira et al. (2001) na comunidade arbustiva fechada localizada no cordão arenoso interno da restinga de Barra de Maricá aponta E. rotundifolia como rara na área estudada (com apenas um indivíduo em área estimada de 1 ha). Entretanto para os autores trata-se de uma espécie mais abundante em outras formações vegetais dos cordões arenosos. Nesse sentido, Doroty Sue Dun Araújo (comunicação pessoal) informa que apesar de não muito freqüente na região das dunas de Arraial do Cabo, é bem comum, perto da praia, em outras restingas como a de Maricá e de Macaé. Nessa última, nos trabalhos extensos, ainda não publicados, de levantamento fitossociológico no Parque Nacional da Restinga de Jurubatiba E. rotundifolia está entre as 10 espécies mais importantes na restinga arbustiva aberta de Clusia. Segundo Menezes \& Araújo (2005), E. rotundifolia ocorre na restinga de Marambaia em uma formação herbácea (herbácea fechada de cordão arenoso) e em três arbustivas (arbustiva aberta não inundável; arbustiva fechada de pós-praia e arbustiva fechada de cordão arenoso) sendo muito comum nas duas primeiras. Esses mesmos autores encontraram C. icaco apenas na formação arbustiva aberta não inundável.

No estado do Rio de Janeiro muitas restingas apresentam essas formações - especialmente as mais abertas - que estão sob forte pressão antrópica. Entretanto, de acordo com as informações obtidas com alguns erveiros, a fiscalização dos órgãos ambientais do estado tem impedido, em parte, a extração de abajurú

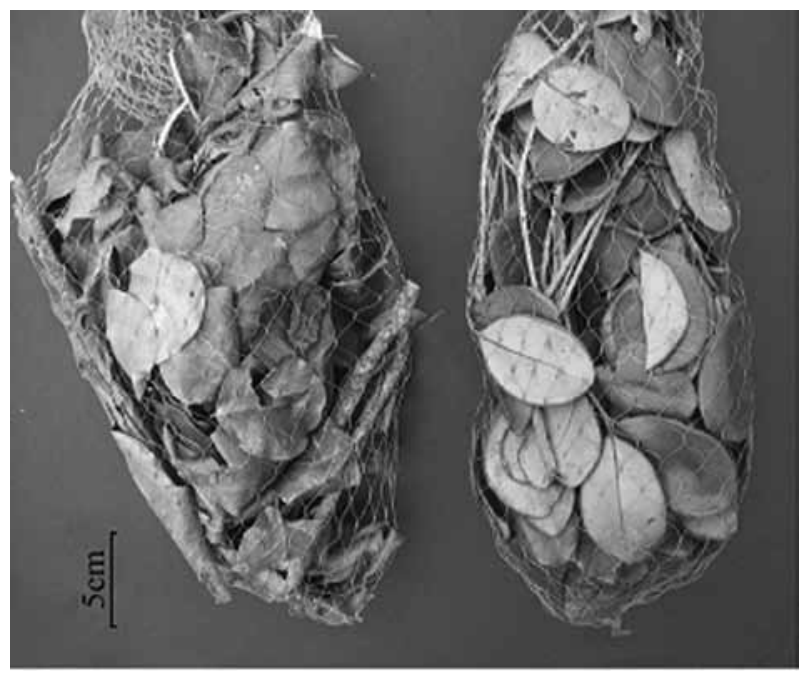

Figura 2. Ramos ensacados de Chrysobalanus icaco L. (esquerda) e Eugenia rotundifolia Casar. (direita) comercializados no mercado de Madureira, RJ.
(C. icaco) em áreas litorâneas. Isto provavelmente estimulou a procura por outra espécie que pudesse substituí-la. Provavelmente, o fato de E. rotundifolia ter distribuição mais ampla no estado do Rio de Janeiro e apresentar certa semelhança com C. icaco colaborou para que extratores e erveiros passassem a vendêla e denominá-la como abajurú. Os nomes populares encontrados na literatura para E. rotundifolia foram "jaboticaba do mangue" (Pio Corrêa, 1926) e "apertagoela" (Zamith \& Scarano, 2004). Coincidentemente, este mesmo nome vulgar é empregado pela população caiçara da Ilha Grande (Rio de Janeiro) para C. icaco. Possivelmente o emprego de um mesmo nome popular para duas espécies pode ter contribuído também para a comercialização de uma pela outra. No mercado de Madureira E. rotundifolia foi também denominada pelos erveiros como "abajurú-do-mangue”.

As pesquisas realizadas para avaliação do uso seguro das plantas medicinais e fitoterápicos no Brasil ainda são insipientes, sendo que a maioria das plantas nativas ainda não foi avaliada quanto à sua segurança e eficácia (Rates, 2001; Carvalho et al., 2008; Marliére et al., 2008; Silveira et al., 2008; Veiga-Junior, 2008), assim como é insipiente o controle da comercialização pelos órgãos oficiais em feiras livres, mercados públicos ou lojas de produtos naturais (Veiga Jr \& Pinto, 2005). Sendo assim nenhuma espécie usada na medicina tradicional deveria ser usada antes que os estudos de segurança tivessem sido completados (BarbosaFilho et al., 2005). A introdução de E. rotundifolia no mercado informal pode refletir, por um lado, o efeito de alguma fiscalização na coleta de exemplares em áreas de vegetação natural protegidas e, por outro lado, a ineficiência do controle da comercialização do abajurú oferecido à população.

Fontenelle et al. (1994) caracterizaram a anatomia e micromorfologia de 11 espécies de Eugenia encontradas na restinga de Maricá (RJ) inclusive de $E$. rotundifolia. A anatomia foliar de C. Icaco também foi trabalhada por Espinosa-Osornio et al. (2002). Esses trabalhos certamente servirão de base para a verificação de ocorrência de fraudes e identificação de espécies ensacadas e comercializadas no mercado informal, com a designação popular de abajurú.

Segundo as informações obtidas no mercado de Madureira com um erveiro que também fornece abajurú para outros erveiros e feirantes de outras localidades, a venda destas etnoespécies atinge cerca de 70 molhos por semana na venda interna diária dentro do mercado, e aproximadamente 1.000 molhos por semana, na venda durante a madrugada (do lado de fora do mercado) para feirantes que irão revendê-las em feiras livres e bancas isoladas da cidade. Neste contexto, não se pode descartar a possibilidade de redução das populações, na natureza, pela intensificação da extração em seus ambientes naturais. Zamith \& Scarano (2004) estudando a viabilidade da produção de mudas destinadas a 
plantios para a restauração de restingas degradadas informam que $E$. rotundifolia se apresenta viável para a produção de mudas, visto o seu potencial elevado para germinação (em torno de 60\%). Assinalam, entretanto, que a germinação é lenta (em média 61 dias para a emergência da parte aérea), o que pode acarretar na não uniformidade entre plântulas e maior risco de perda das sementes por deterioração, uma vez que estas permanecem no solo por um certo tempo, antes da germinação.

Numa primeira análise pode-se pensar então que a introdução de $E$. rotundifolia para a venda popular com o nome de abajurú seja, em parte, um artifício encontrado pelos extratores para driblar a fiscalização. Entretanto, não faz muito sentido tendo em vista que ambas são vendidas muitas vezes ensacadas, o que dificulta o reconhecimento (Figura 2). Quem fiscaliza saberia diferenciar as duas espécies?

Uma segunda hipótese estaria ligada simplesmente a um problema de dificuldade no reconhecimento das espécies pelos extratores e erveiros vendedores, bem como pelos consumidores, por conta da morfologia semelhante.

Uma terceira hipótese - e talvez a mais interessante - seria haver, por parte dos erveiros, a atribuição da atividade hipoglicemiante também à E. rotundifolia, uma vez que outras espécies de Myrtaceae (pitanga, jambo e eucalipto) já são usadas pela população como tal. É importante salientar que, no comércio popular de espécies consideradas medicinais, a confiabilidade das informações transmitidas pelos erveiros é fundamental: as relações interpessoais e a disseminação de informações dentro de um mercado, como o de Madureira, vão mais além do que a simples troca de receitas.

\section{CONSIDERAÇÕES FINAIS}

Estudos etnobotânicos em ambientes urbanos são fascinantes e abrem muitas portas para se conhecer o que não tem sido catalogado (Balick \& Lee, 2001). Ademais, os padrões de usos locais para espécies consideradas medicinais, em áreas urbanas, não são ainda bem entendidos.

Questões relacionadas às teorias da aparência e de disponibilidade de espécies são discutidas em diversos estudos (Stepp \& Moerman, 2001; Albuquerque \& Lucena, 2005; Akerreta et al., 2007) na tentativa de entender que fatores determinam as preferências e critérios de locais de seleção para uso das plantas. Voeks (1996) sugere que erveiros da Floresta Atlântica da costa do Brasil preferem florestas secundárias e áreas perturbadas: plantas usadas como medicinais precisam ser abundantes e acessíveis. Como citado anteriormente E. rotundifolia é uma espécie abundante, possibilitando o extrativismo.

Além dos fatores ambientais, fatores culturais certamente influenciam a distribuição ou a área de uso das espécies já que atuam na seleção de plantas medicinais. Para Akerreta et al. (2007) o fator cultural pode, às vezes, ser decisivo na escolha de plantas, até mais do que a abundância e disponibilidade das espécies. Por exemplo, quando a população local percebe as propriedades químicas e medicinais de uma planta. Nesse sentido, para o caso do abajurú (E. rotundifolia), isso vem de encontro a nossa hipótese relacionada à idéia de que as pessoas poderiam, de fato, estender (e experimentar) o uso no tratamento contra os efeitos do diabetes para novas espécies da família Myrtaceae.

No processo das interações das populações com as espécies vegetais, encontros casuais podem levar a descobertas justificadas posteriormente pela ciência. Se levarmos em consideração que certamente existem várias espécies na restinga morfologicamente semelhantes, a substituição de $C$. icaco justamente por E. rotundifolia no comércio popular, poderá também ser explicada, ou não, por futuras pesquisas farmacológicas.

\section{AGRADECIMENTOS}

As autoras agradecem aos erveiros por gentilmente dispor do seu tempo durante o horário de trabalho, a Marcelo Souza, especialista em Myrtaceae, bem como a Dorothy Sue Dun Araújo, Nivaldo Peroni, Maria Mercedes Teixeira da Rosa e Helena Regina P. Lima, pelas valiosas críticas e sugestões.

\section{REFERÊNCIAS}

Agra MF, Silva KN, Basílio IJLD, França PF, Barbosa-Filho JM 2008. Survey of medicinal plants used in the region Northeast of Brazil. Rev Bras Farmacogn 18: 472-508.

Akerreta S, Cavero RY, López V, Calvo MI 2007. Analyzing factors that influence the folk use and phytonomy of 18 medicinal plants in Navarra. J Ethobiol Ethnomed 3: 16 .

Albuquerque UP, Lucena RFP 2005. Can apparency affect the use of plants by local people in tropical forests? Interciencia 30: 506-511.

Albuquerque UP, Hanazaki N 2006 As pesquisas etnodirigidas na descoberta de novos fármacos de interesse médico e farmacêutico: fragilidades e perspectivas. Rev Bras Farmacogn 16 (Supl): 678-689.

Albuquerque UP, Monteiro JM, Ramos MA, Amorim ELC 2007. Medicinal and magic plants from a public market in northeastern Brazil. J Ethnopharmacol 110: 76-91.

Almeida EC, Karnikowski MGO, Foleto R, Baldisseroto B 1995. Analysis of anthidiarrheic effect of plants used in popular medicine. Rev Saude Publ 29: 428-433.

Appolinário F 2006. Metodologia da ciência. Filosofia e prática da pesquisa. São Paulo: Pioneira Thomson Learning.

Azevedo SKS, Silva IM 2006. Plantas medicinais e de uso e religioso comercializadas em mercados e feiras 
livres no Rio de Janeiro, RJ, Brasil. Acta Bot Bras 20: $185-194$.

Balick MJ, Lee R 2001. Looking within: urban ethnomedicine and ethnobotany. Altern Ther 7: 114-115.

Barbosa WLR, Peres A, Gallori S, Vincieri FF 2006. Determination of myricetin derivatives in Chrysobalanus icaco L. (Chrysobalanaceae). Rev Bras Farmacogn 16: 333-337.

Barbosa-Filho JM, Vasconcelos THC, Alencar AA, Batista LM, Oliveira RAG, Guedes DN, Falcão HS, Moura MD, Diniz MFFM, Modesto-Filho J 2005. Plants and their active constituents from South Central, and North America with hypoglycemic activity. Rev Bras Farmacogn 15: 392-413.

Bernard HR 1995. Research methods in anthropology. Qualitative and quantitative approaches. $2^{\mathrm{a}}$.ed. London: Altamira Press.

Bertucci A, Haretche F, Olivaro C, Vázquez A, 2008. Prospección química del bosque de galería del río Uruguay. Rev Bras Farmacogn 18: 21-25.

Bnouham M, Ziyyat A, Mekhfi H, Tahri A, Legssyer A 2006. Medicinal plants with potential antidiabetic activity. A review of ten years of herbal medicine research (1990-2000). Int J Diab Metabol 14: 1-25.

Borgatti 1996. Anthropac 4.0. Natick, MA: Analytic Technologies.

Braga R 1960. Plantas do Nordeste, especialmente do Ceará. $2^{a}$ ed. Fortaleza: Imprensa Oficial.

Carvalho ACB, Balbino EE, Maciel A, Perfeito JPS 2008. Situação do registro de medicamentos fitoterápicos no Brasil. Rev Bras Farmacogn 18: 314-319.

Castilho RO, Souza I, Guimarães UP, Kaplan MAC 2000. A Survey of chemical and biological activities of Chrysobalanaceae. An Acad Bras Cienc 72: 292-293.

Cavalli VLLO, Sordi C, Tonini K, Grando A, Muneron T, Guigi A, Roman Júnior WA 2007. Avaliação in vivo do efeito hipoglicemiante de extratos obtidos da raiz e folha de bardana Arctium minus (Hill.) Bernh. Rev Bras Farmacogn 17: 64-70.

Coelho RG, Di Stasi LC, Vilegas W 2002. Chemical constituents from Zollernia ilicifolia and comparison with Maytenus species. Z Naturforsch 58c: 47-52.

Coelho de Souza G, Haas APS, Von Poser GL, Schapoval EES, Elisabetsky E 2004. Ethnopharmacological studies of antimicrobial remedies in the south of Brazil. $J$ Ethnopharmacol 90: 135-143.

Costa OA 1977. Brazilian plants with hypoglycaemic effects. Leandra 7: 63-75.

Cotton CM 1996. Ethnobotany. Principles and Applications. England: John Wiley \& Sons Ltda.

Coulaud-Cunha S, Oliveira RS, Waissmmann W 2004. Venda livre de Sorocea bonplandii Bailon como EspinheiraSanta no Município do Rio de Janeiro- RJ. Rev Bras Farmacogn 4 (Supl. 1): 51-53.

Di Stasi LC, Hiruma-Lima CA 2003. Plantas medicinais na Amazônia e na Mata Atlântica. São Paulo: ed. UNESP.

Donato AM, Morretes BL 2007. Anatomia foliar de Eugenia brasiliensis Lam. (Myrtaceae) proveniente de áreas de restinga e de floresta. Rev Bras Farmacogn 17: 426-443.

Espinosa-Osornio G, Vargas-Simón G, Engleman M 2002. Contribuición al estudio de la anatomía foliar del icaco (Chrysobalanus icaco L.). Bioagro 14: 29-36. Fernandes J, Castilho RO, Costa MR, Wagner-Souza K, Kaplan MAC, Gattass CR 2003. Pentacyclic triterpenes from Chrysobalanaceae species: cytotoxicity on multidrug resistent and sensitive leukemie cell lines. Cancer Lett 190: 165-169.

Ferrão JEM 1999. Fruticultura tropical. Espécies com frutos comestiveis. Lisboa: Instituto de Investigações Científica Tropical.

Figueiredo AS, Modesto-Filho J 2008. Efeito do uso da farinha desengordurada do Sesamum indicum L nos níveis glicêmicos em diabéticas tipo 2. Rev Bras Farmacogn 18: 77-83.

Fonseca-Kruel VS, Peixoto AL, Sá CFC, Araújo DSD, Silva WL, Ferreira AJ 2006. Plantas úteis da restinga: o saber dos pescadores artesanais de Arraial do Cabo, Rio de Janeiro. Rio de Janeiro: Instituto de Pesquisas Jardim Botânico do Rio de Janeiro.

Fontenelle GB, Costa CG, Machado RD 1994. Foliar anatomy and micromorphology of eleven species of Eugenia L. (Myrtaceae). Bot J Linn Soc 115: 111-1333.

Freise F W 1934. Plantas medicinais brasileiras. São Paulo: Secretaria de Agricultura.

Funke I, Melzig MF 2006. Traditionally used plants in diabetes therapy - phytotherapeutics as inhibitors for $\alpha$-amylase activity. Rev Bras Farmacogn 16: 1-5.

Gonzalez GG, Portela TY, Di Stasi LC 2001. Antiulcerogenic and anagelsic effets of Maytenus aquifolium, Sorocea bonplandii and Zolernia ilicifolia. J Ethnopharmacol 77: 41-47.

Hoehne FC 1978. Plantas e substâncias tóxicos e medicinais. São Paulo: Secretaria Agricultura.

Holetz FB, Pessini GL, Sanches NR, Cortez DAG, Nakamura CV, Filho BPD 2002. Screening of some plants used in the Brazilian folk medicine for the treatment of infectious diseases. Mem Inst Oswaldo Cruz 97: 1027-1031.

Instituto de Pesquisas Jardim Botânico do Rio de Janeiro 2007. Jabot - Banco de Dados da Flora Brasileira. Disponível em: <http://www.jbrj.gov.br/jabot>. Acessado em julho de 2007.

Janebro DI, Queiroz MSR, Ramos AT, Sabaa-Srur AUO, Cunha MAL, Diniz MFFM 2008. Efeito da farinha da casca do maracujá-amarelo (Passiflora edulis $\mathrm{f}$. flavicarpa Deg.) nos níveis glicêmicos e lipídicos de pacientes diabéticos tipo 2. Rev Bras Farmacogn 18 (Supl.): 724-732.

Lorenzi H, Matos FJA 2002. Plantas medicinais no Brasil. Nova Odessa: Instituto Plantarum.

Marliére LDP, Ribeiro AQ, Brandão MGL, Klein CH, Acurcio FA 2008. Utilização de fitoterápicos por idosos: resultados de um inquérito domiciliar em Belo Horizonte (MG), Brasil. Rev Bras Farmacogn 18 (Supl.): 754-760.

Martin GJ 1995. Etnobotânica. Manual de Métodos. Kew: WWF/UNESCO/Royal Botanical Gardens, Série Pueblos y Plantas.

Menezes LFT, Araujo DSD 2005. Formações vegetais da restinga da Marambaia, Rio de janeiro. In: Menezes L.F et al (Org.) História Natural da Marambaia. Seropédica, RJ: EDUR, p 67-120.

Mors WB, Rizzini CT, Pereira NA 2000. Medicinal Plants of Brazil. Michigan: Reference Publications, Inc. 
Netto AG 2007. A necessidade imediata de um novo Censo Nacional de Diabetes. Disponível na internet em: <http://www.diabetes.org.br/artigos/ censonacionaldiabetes.php>. Consulta: 15 de maio de 2007.

Olajide OA, Awe SO, Makinde JM 1999. Pharmacological studies on the leaf of Psidium guajava. Fitoterapia 70: 25-31.

Oliveira ACA, Souza RM 2005. Avaliação geoambiental dos sistemas dunares costeiros de Sergipe. Revista FAPESE 1: 51-72.

Oliveira NR, Dias IJM, Câmara CAG 2005. Estudo comparativo do óleo essencial de Eugenia punicifolia (HBK) DC. de diferentes localidades de Pernambuco. Rev Bras Farmacogn 15: 39-42.

Oliveira AM, Humberto MMS, Rocha RFA, Sant'Ana AEG 2006. Estudo fitoquímico e avaliação das atividades moluscicida e larvicida dos extratos da casca do caule e folha de Eugenia malaccensis L. (Myrtaceae). Rev Bras Farmacogn 16: 618-624.

Pereira NA 1997. Plants as hypoglycemic agents. Cienc Cult 49: 354-358.

Pereira MCA, Araújo DSD, Pereira OJ 2001. Estrutura de uma comunidade arbustiva da restinga de Maricá - RJ. Rev Bras Bot 24: 273-281.

Pio Corrêa M 1926. Dicionário de Plantas Úteis do Brasil e das exóticas cultivadas. Vol.3. Rio de Janeiro: Imprensa Nacional.

Prance GT 1972 Chrysobalanaceae. Flora Neotropica. Monograph $n^{\circ} 10$. New York: Hafner Publishing.

Presta GA, Pereira NA 1987. Atividade do abagerú (Chrysobalanus icaco L, Chrysobalanaceae) em modelos experimentais para o estudo da planta. Rev Bras Farm 68: 91-101.

Presta GA, Fonseca AS, Bernardo-Filho M 2007. A Chrysobalanus icaco extract alters the plasmid topology and the effects of stannous chloride on the DNA of plasmids. Rev Bras Farmacogn 17: 331-335.

Quinlan M 2005. Considerations for collecting freelists in the field: Examples from ethnobotany. Field Meth 17: $1-16$.

Quintans-Júnior LJ, Almeida JRGS, Lima JT, Nunes XP, Siqueira JS, Oliveira LEG, Almeida RN, AthaydeFilho PF, Barbosa-Filho JM 2008. Plants with anticonvulsant properties - a review. Rev Bras Farmacogn 18 (Supl.): 798-819.

Rates SMK 2001. Promoção do uso racional de fitoterápicos:uma abordagem no ensino de farmacognosia. Rev Bras Farmacogn 11: 57-69.

Ravi K, Ramachandran B, Subramanian S 2004. Protective effect of Eugenia jambolana seed kernel on tissue antioxidants in streptozotocin-induced diabetic rats. Biol Pharm Bull 27: 1212-1217.

Roig y Mesa JT 1945. Plantas Medicinales, aromáticas, o venenosas de Cuba. Habana: Ministerio de Agricultura, servicio de Publicidad y Divulgación.

Santana LM, Silva AF 2000. Características de solo do litoral onde ocorre o guajuru (Chrysobalanus icaco L.) e teores de N, P, K e Na nos órgãos desta espécie. Rev Ceres 47: 171-179.

Sartorelli DS, Franco LJ 2003. Tendências do diabetes mellitus no Brasil: o papel da transição nutricional. Cad Saúde Pública 19: 29-36
Sartorelli DS, Franco LJ, Cardoso MA 2006. Intervenção nutricional e prevenção primária do diabetes mellitus tipo 2: uma revisão sistemática. Cad Saúde Pública 22: 7-18.

Silveira PF, Bandeira MAM, Arrais PSD 2008. Farmacovigilância e reações adversas às plantas medicinais e fitoterápicos: uma realidade. Rev Bras Farmacogn 18: 618-626.

Smith JJ 1993. Using ANTHROPAC 3.5 and a spreadsheet to compute a freelist salience index. Cultural Anthropology Methodology Newsletter 5: 1-3.

Souza MC 2005. Myrtaceae Juss. da restinga da Marambaia, $R J$ - Brasil. Rio de Janeiro, 152p. Dissertação de Mestrado - Programa de Pós-Graduação, Jardim Botânico do Rio de Janeiro/ ENBT.

Stepp JR, Moerman DE 2001. The importance of weeds in ethnopharmacology. J Ethnopharmacol 75: 19-13.

Sutrop U 2001. List task and a cognitive salience index. Field Meth 13: 263-276.

Torrico F, Cepeda M, Guerrero G, Melendez F, Blanco Z, Canelón DJ, Diaz B, Compagnone RS, Suárez AI 2007. Hypoglycaemic effect of Croton cuneatus in streptozotocin-induced diabetic rats. Rev Bras Farmacogn 17: 166-169.

Ugent D, Ochoa CM 2006. La etnobotánica del Perú: desde la Prehistoria al Presente. Lima: Imprenta Univ. Nacional Mayor San Marcos.

Veiga Jr VF, Pinto AV 2005. Plantas medicinais:cura segura? Quim Nova 28: 519-528.

Veiga-Junior VF 2008. Estudo do consumo de plantas medicinais na Região Centro-Norte do Estado do Rio de Janeiro: aceitação pelos profissionais de saúde e modo de uso pela população. Rev Bras Farmacogn 18: 308-313.

Voeks RA 1996. Tropical forest healers and habitat preference. Econ Bot 50: 381-400.

Wong W 1976. Some folk medicinal plants from Trinidad. Econ Bot 30: 103-142.

Zamith LR, Scarano FR 2004. Produção de mudas de espécies de restingas do município do Rio de Janeiro, RJ, Brasil. Acta Bot Bras 18: 161-176. 